\title{
Teaching residents out-of-hospital anesthesia-what are we waiting for?
}

\author{
Matt M. Kurrek, MD • Steven L. Dain, MD • \\ Rebecca S. Twersky, MD · Frances Chung, MD
}

Received: 26 May 2010/Accepted: 16 August 2010/Published online: 28 August 2010

(c) Canadian Anesthesiologists' Society 2010

\section{To the Editor,}

Out-of-hospital anesthesia is a rapidly growing field with up to $55 \%$ of all ambulatory procedures in the US currently being performed outside the hospital ${ }^{1}$. In Canada, this practice includes anesthesia in non-hospital surgical facilities, out-of-hospital premises (OHPs), and various office settings (office-based anesthesia), some of which depending on provincial regulations - may be regulated or accredited. An article reviewing this topic was recently published in the Journal ${ }^{2}$.

Teaching in large tertiary care hospitals may not prepare trainees adequately for out-of-hospital anesthesia that requires different knowledge and practice ${ }^{3}$. The Association of Canadian University Departments of Anesthesia (ACUDA) is developing a national ambulatory curriculum; however, the program does not include specific consideration or mention of out-of-hospital anesthesia and its particular aspects of facility administration and patient care considerations in the pre- intra- or postoperative phase (personal communication). ${ }^{\mathrm{A}}$

In order to assess the need for an expanded curriculum, we sought to evaluate 1) the current training of Canadian

M. M. Kurrek, MD $(\bowtie) \cdot$ F. Chung, MD

University of Toronto, Toronto, ON, Canada

e-mail: m.kurrek@utoronto.ca

S. L. Dain, MD

University of Western Ontario, London, ON, Canada

R. S. Twersky, MD

SUNY Downstate Medical Center, Brooklyn, NY, USA

F. Chung, MD

Toronto Western Hospital, Toronto, ON, Canada anesthesia residents and 2) their knowledge of out-ofhospital anesthesia.

Both portions of the study were approved by the primary author's Hospital Research Ethics Board. During the first phase of our study, we asked the 16 directors of the Canadian training programs who were in attendance at the June 2009 ACUDA meeting to complete a previously published survey questionnaire ${ }^{4}$ that was designed to provide information regarding their programs' educational activities and the exposure of their residents to out-ofhospital anesthesia. The response rate for the ACUDA survey was $14 / 16(87 \%)$. Six $(43 \%)$ of the 14 programs (95\% confidence interval [CI], 34-52\%) provided some services outside of hospitals, but only four (29\%) of the 14 departments (95\% CI, 21-37\%) occasionally provided experience for their residents. Eleven $(79 \%)$ of the 14 departments (95\% CI, 71-87\%) had no educational activities, and 12 (86\%) departments (95\% CI, 80-92\%) had no formal rotation for out-of-hospital anesthesia.

During the second phase of our study, we developed a ten-item test questionnaire that was validated by four experts in out-of-hospital ambulatory anesthesia using the Delphi method. The questionnaire was designed to assess knowledge about topics relevant to out-of-hospital anesthesia. It entailed written responses to questions on fire and electrical safety, management of malignant hyperthermia, control of infection, delegation of care, facility regulation, discharge criteria, and considerations for various pertinent clinical scenarios (e.g., obesity, obstructive sleep apnea, pediatrics, and thromboprophylaxis). The responses were scored by two independent raters who had not been

\footnotetext{
A Dr. M. Levine, May 2010, ACUDA, The Hospital for Sick Children, University of Toronto, Ontario, Canada; Phone: 416-9460608; E-mail: mark.levine@utoronto.ca
} 
involved in the questionnaire development. A scoring template listed the required element(s) for each question, and each resident's score was the average score from the two independent raters. The maximum score was 100 .

In December 2009, this test questionnaire was distributed to PGY-4 and PGY-5 residents at five Ontario residency programs in proximity to the primary author's base hospital, allowing a timely and efficient gathering of data. Residents from two of those departments were occasionally allowed to accompany faculty to out-of-hospital premises, but no department offered a specific rotation or educational activities for OHPs. This pattern seemed consistent with the results from the ACUDA survey during the first phase. Residents in the final two years of their training were chosen to receive the questionnaires because they were close to their final examination/graduation.

The questionnaires were filled out by 29 PGY -4 and PGY-5 residents (representing approximately $35 \%$ of the combined PGY-4 and PGY-5 residents at those training programs). Inter-rater reliability for the questionnaire was very good with an intra-class correlation coefficient of 0.822 (95\% CI, 0.62-0.91) (SPSS ${ }^{\mathrm{TM}}$ statistical software package, SPSS Inc., Chicago, IL, USA). The mean knowledge score for all 29 residents was $28.4 \pm 8.5$; the mean score for the 20 PGY-4 residents was $28.1 \pm 9.0$, and the mean score for the 9 PGY-5 residents was $29.1 \pm 7.9$.

Despite its rapid growth, exposure of Canadian anesthesia residents to out-of-hospital anesthesia is limited, and senior residents have a significant knowledge deficit regarding safe OHP practice. The response from the residents' questionnaire, comprising an approximate sample size of $35 \%$, likely shows a reasonably representative picture of the senior residents' knowledge about anesthesia in OHPs and emphasizes the need for an out-of-hospital anesthesia educational program. Even the $17 \%$ of residents who had some experience in OHP anesthesia did not appear to have increased knowledge, and this result may point toward the need of a more structured curriculum.

The current initiative by the Association of Canadian University Departments of Anesthesia (ACUDA) to design a national curriculum could present a unique opportunity to incorporate out-of-hospital anesthesia in the ambulatory curriculum. Individual training programs may already choose to start educational activities, including lectures and rotations. Our OHP test questionnaire could be used in the future to further evaluate the impact of out-of-hospital anesthesia programs.

Acknowledgements We acknowledge the assistance of the following individuals during data collection, analysis, and document preparation: Dr. Mark Levine (University of Toronto), Judy Pace (McMaster University), Dr. Linda Wynne (University of Ottawa), Dr. Michael Cummings (Queens University), and Marko Katic (Sunnybrook Health Science Centre).

Conflicts of interest None declared.

\section{References}

1. American Hospital Association. Trendwatch Chartbook 2007: Trends Affecting Hospitals and Health Systems. Available from URL: http://www.aha.org/aha/trendwatch/chartbook/2007/07chapter2. ppt\#8 (accessed June 2010).

2. Kurrek MM, Twersky RS. Office-based anesthesia. Can J Anesth 2010; 57: 256-72.

3. American Society of Anesthesiologists. Office-Based Anesthesia: Considerations for Anesthesiologists in Setting Up and Maintaining a Safe Office Anesthesia Environment, 2nd Edition, November 2008. Available from URL: http://www2.asahq.org/publications/ ps-319-2-office-based-anesthesia-considerations-for-anesthesiolog ists-in-setting-up-and-maintaining-a-safe-office-anesthesia-environ ment-2nd-edition-november-2008.aspx (accessed June 2010).

4. Hausman LM, Levine AI, Rosenblatt MA. A survey evaluating the training of anesthesiology residents in office-based anesthesia. J Clin Anesth 2006; 18: 499-503. 